Supplement of Earth Syst. Dynam., 8, 865-873, 2017

https://doi.org/10.5194/esd-8-865-2017-supplement

(C) Author(s) 2017. This work is distributed under

the Creative Commons Attribution 3.0 License.

(c) (1)
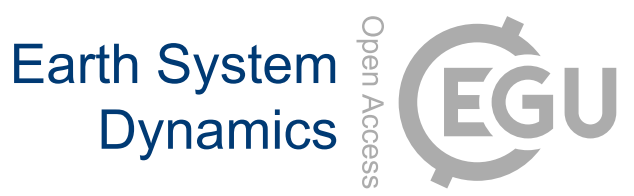

Supplement of

\title{
Climatology of Lyapunov exponents: the link between atmospheric rivers and large-scale mixing variability
}

Daniel Garaboa-Paz et al.

Correspondence to: Vicente Pérez-Muñuzuri (vicente.perez@cesga.es)

and Daniel Garaboa-Paz (angeldaniel.garaboa@usc.es)

The copyright of individual parts of the supplement might differ from the CC BY 3.0 License. 


\section{Seasonal effects on the FTLE climatology}

Figures 1,2 account for the seasonal effect observed in the FTLE climatology for the period $1979-2014$. Note the largest values of the FTLE alternate between southern and northern hemispheres along the whole period. As observed in Figure 1 in the main text, three latitudinal bands are also clearly visible in the Hovmöller diagram. Note that the maximum values are

5 observed for mid-latitudes.

(a)

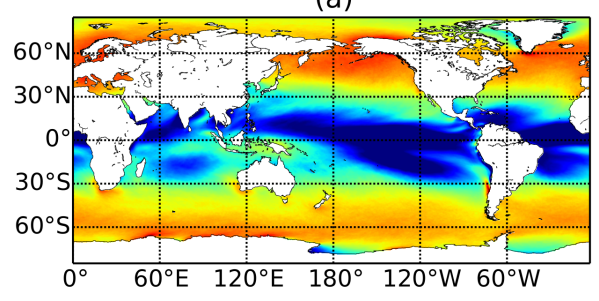

(c)

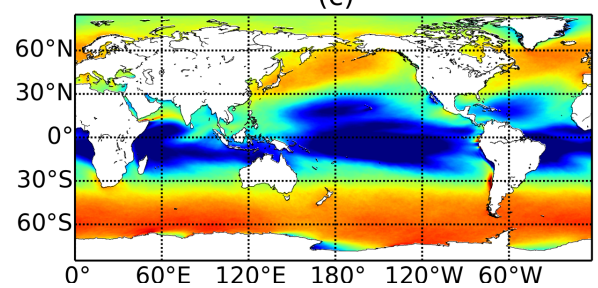

(b)

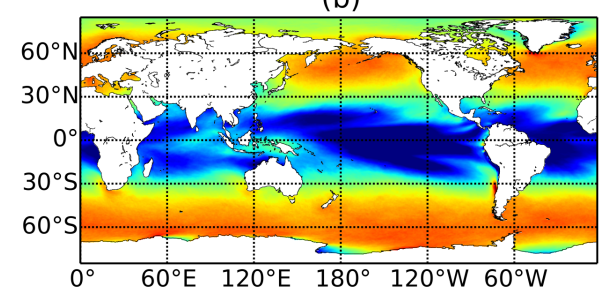

(d)

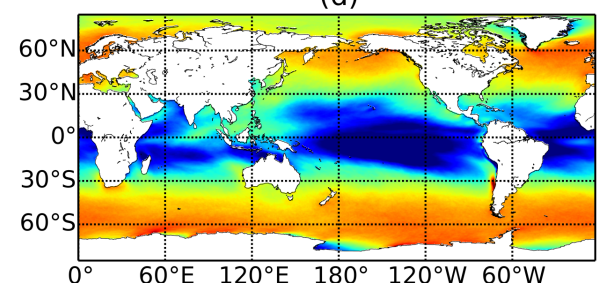

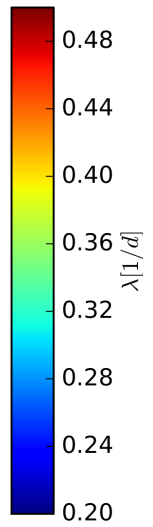

Figure 1. Seasonal mean for the backward FTLE based on the 35 years timeseries for the seasonal periods; (a) DJF, (b) MAM, (c) JJA, and (d) SON. Note the largest values of the FTLE for the northern/southern hemisphere during the winter season. 


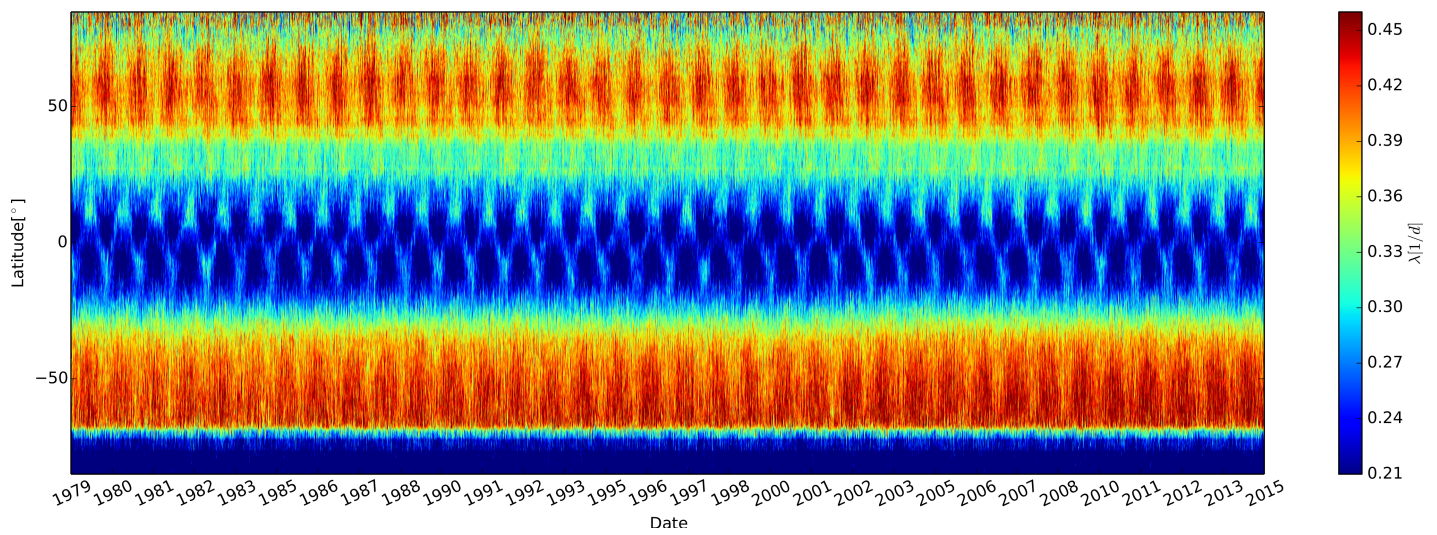

Figure 2. Hovmöller diagram based on week averages for the 35 years FTLE backward timeseries.

\section{Correlation between the FTLE time series and ENSO indices}

Figure 3 shows the monthly backward and forward FTLE time series and the Southern Oscillation Index (SOI) for the 19792014 period. The FTLE series are anticorrelated with the SOI index, with correlation coefficients -0.85 and -0.67 , respectively.

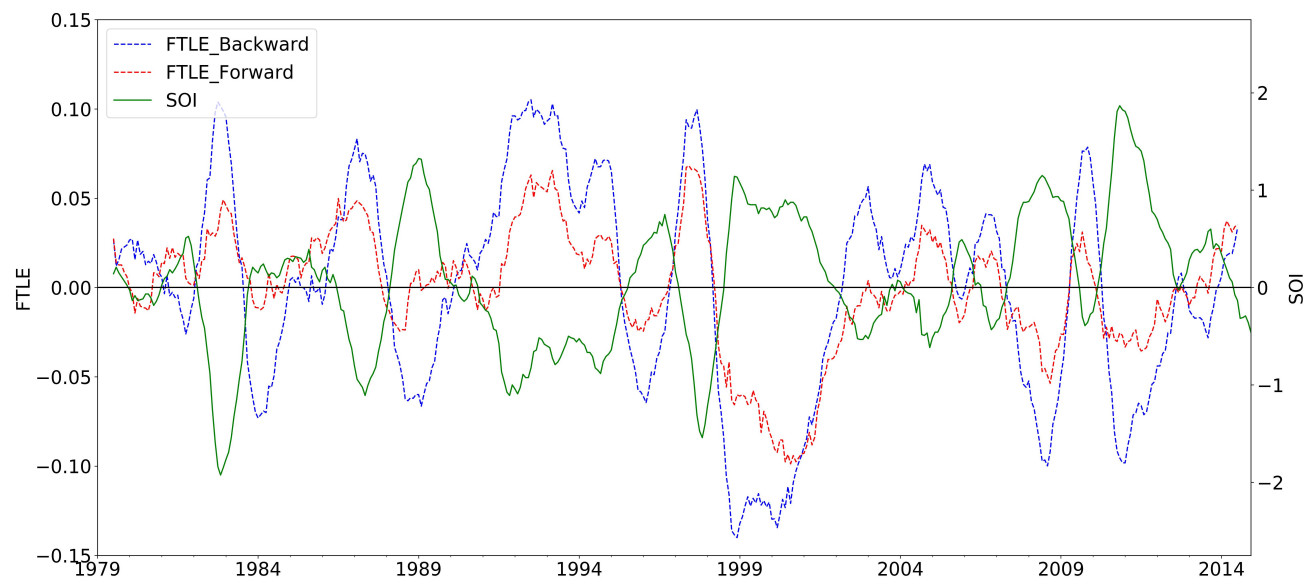

Figure 3. Monthly time evolution of the backward/forward FTLE anomalies and the SOI Index for the 1979-2014 period.

\section{Precipitation rates in Sahara and British Isles due to Atmospheric Rivers}

Figure 4 shows the rainfall rates measured in the Sahara-Morocco (a) and British Isles (b) regions coinciding with a landfall atmospheric river. Precipitation rates are shown as a percentage out of the total retrieved from Sheffield et al. (2005). 


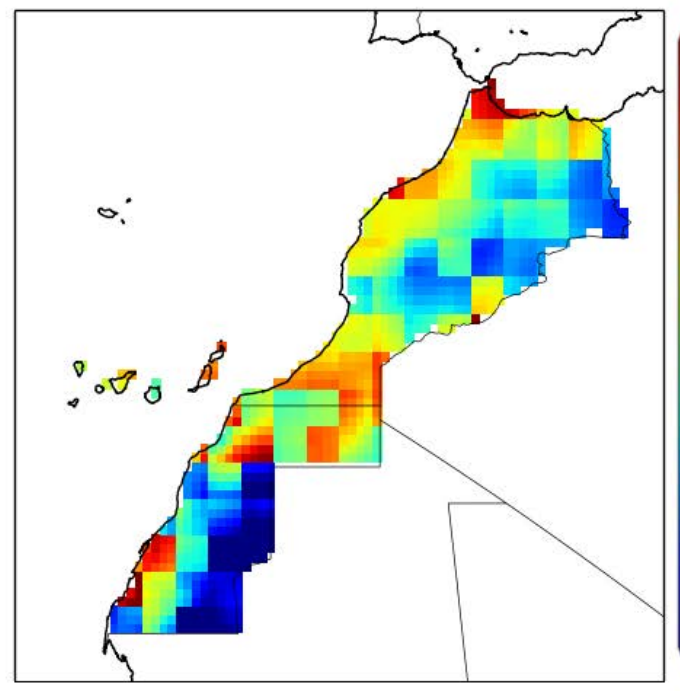

(a)

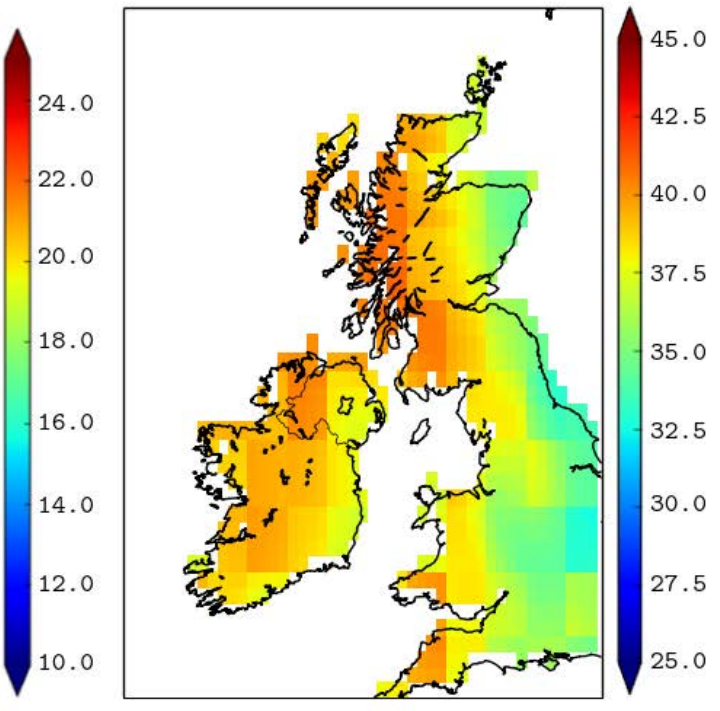

(b)

Figure 4. Ratio of daily precipitation coinciding with an atmospheric river detection out of the total, for the Sahara-Morocco (a) and UKIreland (b) regions. The database of precipitation used in this analysis is the global rain data retrieved from Sheffield et al. (2005). This global high-resolution dataset has been constructed by the combination of observational and reanalysis data from the NCEP-NCAR.

\section{References}

Sheffield, J., G. Goteti, and E.F. Wood (2006). Development of a 50-year high-resolution global dataset of meteorological forcings for land surface modeling. Journal of Climate, 19(13), 3088-3111, doi:10.1175/JCLI3790.1. 